\title{
Investigation of the influence of the microcapillary structure of natural skins on relative humidity in vacuum-sorption humidification
}

\author{
Ludmila Larina $^{1}$, Dmitryi Ruslyakov ${ }^{1, *}$, Olga Tikhonova $^{1}$ \\ ${ }^{1}$ Don State Technical University, 344000 Rostov-on-Don, Russian Federation
}

\begin{abstract}
The article presents the results of studies confirming the law of the gamma distribution of microcapillaries in the structure of materials having a stochastic structure, for example, natural skins. The relative humidity of the latter depends on the mass of moisture collected by the microcapillaries, with heat and mass transfer under vacuum conditions. Numerical values of relative humidity in this case may differ from those recommended by footwear manufacturing technologies and should be considered as an integral part of the phenomenon of high-intensity heat and mass transfer under vacuum conditions and be determined by the proposed models.
\end{abstract}

\section{Introduction}

Studies of the processes of heat and mass transfer through a porous medium in materials to which the natural skin [1] refers are based on the method of studying the diffusion of a liquid or a steam mixture flowing through a single capillary tube simulating a porous medium. Such an approach makes it possible to calculate the diffusion coefficient, the rate of mass transfer over a single capillary, but because of the complexity of the structure of the porous medium, the experimental data differ significantly from the calculated parameters. With high-intensity heat and mass transfer, for example, under vacuum conditions [2], the mechanism of mass transfer by molecular diffusion changes to effusive, in the form of vapor [3].

Its further condensation in the pores (microcapillaries) commensurate with the size of its molecules requires consideration of the stochastic structure of the porous medium and the laws of distribution of microcapillaries in it, which will allow calculating not only the diffusion coefficient, the mass transfer rate, but also the moisture gain in the materials under consideration, due to sorption phenomena, their relative humidity $[4,5]$. So, for example, the relative humidity of the skin with intensified hygrothermal action $[6,7]$ can differ from the values of $26 \ldots 30 \%$, which are recommended by the standard technologies of making footwear. Thus, according to the data given in the work of R.V. Lutsyk [8], for a half-skinned chrome-tanned type of tanning, the moisture of the microcapillaries is from 22 to $27 \%$, and for a heat-resistant yufti, from 16 to $21 \%$. In this connection, obviously, with intensified hygrothermal action $[9,10]$, it becomes necessary to consider the scatter of indicators of relative skin moisture, caused by microcapillary porosity $\Pi$ under experimental studies [11], as an integral part of the phenomenon and to study its nature in more detail. The nature of the observed scatter should be analyzed by statistical methods for the subsequent use in recommendations based on the statistical conclusions about the trend and dispersion, the indicators of the relative humidity of the skin.

\section{Experimental part}

To study the law of distribution of relative moisture indices of leather samples obtained from the results of experimental studies, a sample set of values for each batch of samples was considered $n=30 \cdot 2=60$, as is known [12], for sample size $n \geq 60$ statistical criteria give fairly accurate and unbiased recommendations at the level of significance $\alpha=5 \%$.

For statistical studies of the sample set, a program written using the Maple 9.5 package commands was used.

Based on the results of calculations of the sample set of relative humidity for the leather samples (HVAC), a statistical series was compiled. The number of digits of the statistical series is calculated by the Stürgers rule [6]:

$$
k=[1+3,32 \cdot \lg n]+1
$$

here $[k]$ is the operation of computing the integer part of a number.

Thus, with the volume of the sample population $n=60$, the number of intervals of the statistical series is $k=6$.

\footnotetext{
* Corresponding author: ruslyakof@yandex.ru
} 
The boundaries of the categories of the statistical series with the frequencies of sample values falling into the corresponding category are presented in table 1 .

Table 1. Statistical series for indicators of relative skin moisture

\begin{tabular}{|l|c|c|c|c|c|c|}
\hline \multicolumn{1}{|c|}{ Ranks } & 1 & 2 & 3 & 4 & 5 & 6 \\
\hline Borders & 23,1 & 25,567 & 28,033 & 30,5 & 32,967 & 35,433 \\
ranks & 25,567 & 28,033 & 30,5 & 32,967 & 35,433 & 37,902 \\
\hline Frequencies & 2 & 6 & 9 & 16 & 17 & 10 \\
\hline
\end{tabular}

Graphical representation of the statistical series (histogram) is shown in fig. 1.

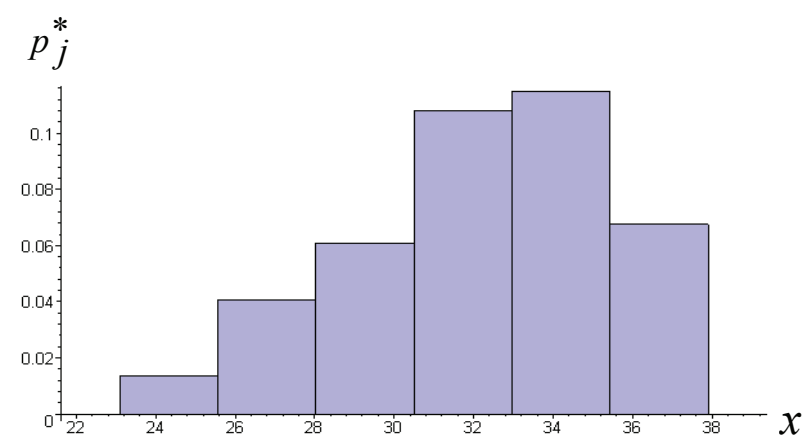

Fig. 1. Histogram of indices of relative humidity samples of leather

On the horizontal axis, in fig. 1, the boundaries of the discharges of the statistical series are plotted, on the vertical axis - the relative frequencies, divided by a step. Here: $m j$ is the number of sample values (Table 1 ) that fall into the $j$-th category $j=1,2, \ldots 6 ; x_{\max }-x_{\min }=14,8-$ sampling range; $h=\frac{x_{\max }-x_{\min }}{k}=2,467 \quad-$ sampling step; $p_{j}^{*}=\frac{m_{j}}{n \cdot h}$ relative frequencies of sample values, divided by a step (values of the empirical density function).

By sample $\{x[k]\}_{k=1}^{n}$ observed values of a random variable, the basic numerical characteristics of the empirical distribution law are calculated:

1) the average of the sample $x_{\text {выб }}=\frac{1}{n} \sum_{k=1}^{n} X[k]$;

2) sample variance

$$
D_{\text {выб }}(\mathrm{OBK})=\frac{1}{n} \sum_{k=1}^{n}\left(X[k]-x_{\text {выб }}\right)^{2} ;
$$

3) selective standard deviation

$$
\sigma_{\text {выб }}(\mathrm{OВК})=\sqrt{D_{\text {выб }}(\text { ОУК })} \text {; }
$$

4) selective coefficient of asymmetry

$$
A s_{\text {выб }}=\frac{\frac{1}{n} \sum_{k=1}^{n}\left(X[k]-x_{\text {выб }}\right)^{3}}{\sigma_{\text {выб }}^{3}(X)} ;
$$

5) selective kurtosis coefficient

$$
\mathrm{E}_{\text {выб }}=\frac{\frac{1}{n} \sum_{k=1}^{n}\left(X[k]-x_{\text {выб }}\right)^{4}}{\sigma_{\text {выб }}^{4}(X)}-3 .
$$

The selective average for the obtained series of observations is $x_{\text {выб }}=32,0567$.

The sample mean is a consistent, unbiased and efficient estimate for the mathematical expectation of a hypothetical distribution law. The sample mean indicates the average value of the distribution of the skin's relative skin densities.

The value of the sample variance is $D_{\text {выб }}=9,9418$.

The sample variance is a consistent estimate for the theoretical variance of the hypothetical distribution law.

The selective mean square deviation is $\sigma_{\text {выб }}=3,1531$.

The value $\sigma_{\text {выб }}$ indicates the average variance of the observed values of the relative skin moisture values around the mathematical expectation.

The value of the selective asymmetry coefficient for a given sample $A s_{\text {выб }}=-0,743$ is substantially less than zero and indicates the left-sided slowness of the histogram relative to the normal distribution law with the same mathematical expectation.

The value of the selective kurtosis coefficient was $\mathrm{E}_{\text {выб }}=0,1453$ and points to the sharpness of the empirical density function with respect to the density of the normal distribution law with the same parameters of mathematical expectation and variance.

To test statistical hypotheses about the distribution law of the random variable under study, according to the method of moments, the unknown numerical characteristics of the hypothetical distribution law are equated to their empirical estimates:

$$
\begin{aligned}
& \mathrm{M}(\text { ОВК })=x_{\text {выб }} ; \\
& D(\text { ОВК })=D_{\text {выб }} ; \\
& A s=A s_{\text {выб }} ; \\
& \mathrm{E}=\mathrm{E}_{\text {выб }} .
\end{aligned}
$$

\section{Approach}

It is known from the above theoretical studies $[13,14]$ that the distribution of skin relative humidity parameters must obey the gamma distribution, and accordingly we will test the hypothesis of the gamma distribution of the sample population under study. A description of the main parameters of this distribution and the form of the corresponding density function is given in [15].

The practical value of the criterion $\chi^{2}$ when checking statistical hypotheses on the distribution law is calculated by the formula:

$$
\chi_{\text {пр }}^{2}=\sum_{j=1}^{k_{1}} \frac{\left(m_{j}-n p_{j}\right)^{2}}{n p_{j}}
$$


where $n$ is the sample size; $m_{j}$ - the number of sampled values that fall into the $j$-th category, $p_{j}$ - probability of falling into the $j$-th category of the random variable of the hypothetical distribution law; $k_{1}-$ the number of digits of the statistical series is recalculated by the Pearson criterion from the condition:

$$
n p_{j}>5
$$

Those bits for which condition (8) is not satisfied are combined with neighboring ones until the condition is satisfied.

The value of the criterion statistics $\chi^{2}$ for the gamma distribution of the samples is:

$$
\chi_{\text {пр }}^{2}=3,316 .
$$

The theoretical value of the criterion $\chi_{\alpha, r}^{2}$ is calculated depending on the number of degrees of freedom $r$ and the significance level of the criterion $\alpha$. The level of significance of a statistical criterion is the probability of accepting an incorrect basic hypothesis, it is set by the experimenter and is equal to 0.05 . The number of degrees of freedom according to [9] is equal to the number of digits of the statistical series after recalculation minus the number of constraints imposed on the frequencies:

$$
r=k_{1}-1-2
$$

For the gamma distribution $k_{1}=5$.

Links superimposed on frequencies:

1) the sum of the relative frequencies is unity,

2) two unknown parameters of the gamma distribution are equated to their empirical estimates.

Thus, the theoretical value of the criterion $\chi^{2}$ at the significance level $\alpha=0,05$ will be equal to

$$
\chi_{\alpha ; r}^{2}=\chi_{0,05 ; 2}^{2}=5,991 .
$$

Because the $\chi_{\text {пр, вдоль }}^{2}=3,316<\chi_{\alpha ; \mathrm{r}}^{2}=5,991$, then there is no reason to reject the hypothesis of gamma distribution, and it is accepted as plausible.

The gamma distribution is given by the density function [7]

$$
f(x)=\frac{x^{a-1} s^{a}}{\Gamma(a)} \mathrm{e}^{-s x},
$$

$\Gamma(a)=\int_{0}^{\infty} t^{a-1} e^{-t} d t-$ gamma function.

The parameters a and s satisfy the following system of equations:

$$
\left\{\begin{array}{c}
x_{\text {выб }}=\frac{a}{s}, \\
D_{\text {выб }}=\frac{a}{s^{2}} .
\end{array}\right.
$$
obtain:

Solving the system (7) with respect to $a$ and $s$, we

$$
a=\frac{x_{\text {выбб }}^{2}}{D_{\text {выб }}}=101,64 ; \quad s=\frac{x_{\text {выб }}}{D_{\text {выб }}}=3,1707 .
$$

The graph of the hypothetical density function in combination with the histogram is shown in fig. 2 and table 2 .

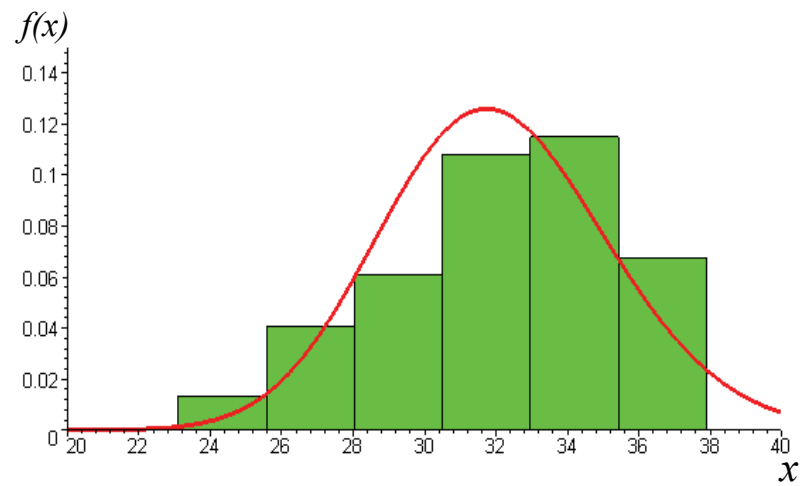

Fig. 2. Histogram of relative humidity indices for skin samples and a hypothetical function of the gamma distribution density

Table 2. Values of the gamma distribution density function for the samples

\begin{tabular}{|c|c|}
\hline Borders ranks & Values function \\
\hline 23,1 & $0,128 \cdot 10^{-2}$ \\
\hline 25,567 & 0,0140 \\
\hline 28,033 & 0,0598 \\
\hline 30,5 & 0,1164 \\
\hline 32,967 & 0,1171 \\
\hline 35,433 & 0,0669 \\
\hline 37,902 & 0.0234 \\
\hline
\end{tabular}

From the function of the density of the gamma distribution, calculate:

$$
\mathrm{P}(\mathrm{OBK}<31,9516)=\int_{0}^{31,9516} f(x) d x=0,5 .
$$

Find the boundaries of the interval $\gamma=0,95$

$$
\begin{gathered}
\mathrm{P}(|\mathrm{OBK}-\mathrm{M}(\mathrm{OBK})|<6,2155)= \\
=\mathrm{P}(25,841<\mathrm{OBK}<38,272)=0,95 .
\end{gathered}
$$

The index of the relative skin moisture for the samples, calculated from the statistical series, according to the rule of two sigma changes in the range $(25,841$; 38,272 ) with a confidence probability of 0,95 .

\section{Conclusions}

The results obtained indicate a scatter in the relative humidity of the skin due to the different microcapillary porosity $\Pi$ of samples cut from different parts of the skin and therefore the results of the intensified hygrothermal treatment should be evaluated, in our opinion, not by the numerical index of the relative humidity, but by the time necessary to fill a single microcapillary of the skin as a result of sorption phenomena and heat exchange between the skin and steam according to the equations given in [16]: 


$$
m_{c}=\pi \cdot r_{0}^{2} L \cdot \rho_{\mathrm{B}} \cdot\left(1-e^{-\frac{2 D \rho_{n}}{L^{2} \cdot \rho_{\mathrm{B}}} \cdot \tau}\right)
$$

where $r_{0}$ is the radius of the microcapillary at the initial instant of time; $L$ - length of the capillary, taking into account its tortuosity; $\rho_{n}$ is the vapor density corresponding to the process conditions (pressure and temperature); $\rho_{\beta}$ is the density of water; $D$ is the diffusion coefficient, and $\tau$ is the processing time.

$$
m_{t}=\mathrm{M}_{\mathrm{\kappa}} \cdot \frac{C_{\mathrm{K}}}{4,19} \cdot\left[e^{0,00176 \cdot\left(T-T_{\mathrm{H}}\right)}-1\right] \cdot 100 \%
$$

Having set by the specific heat of skin of $S_{k}$ equal $1,61 \mathrm{~kJ} /$ ( $\mathrm{kg} \mathrm{To}$ ) [4], we will receive numerical values of an additional weight of moisture in skin weight depending on temperature.

The numerical values of mass of the condensed moisture as a result of capillary and sorption processes and heat exchange received on the equations $(9,10)$ and corresponding to them values of relative humidity of skin are given in table 3 .

Table 3. Values of relative humidity of samples of skin depending on parameters and time of vacuum and sorption

\begin{tabular}{|c|c|c|c|c|}
\hline \multirow{2}{*}{$\begin{array}{c}\text { Key } \\
\text { parameters } \\
\text { vacuum and } \\
\text { sorption } \\
\text { moistening }\end{array}$} & \multicolumn{4}{|c|}{ Moistening time, s } \\
\hline & 120 & 240 & 360 & 480 \\
\hline $\begin{array}{l}\text { Average value } \\
\text { of pressure, } \mathrm{Pa}\end{array}$ & $25 \cdot 10^{3}$ & $30 \cdot 10^{3}$ & $40 \cdot 10^{3}$ & $50 \cdot 10^{3}$ \\
\hline $\begin{array}{l}\text { Average value } \\
\text { of temperature, } \\
{ }^{\circ} \mathrm{C}\end{array}$ & 55 & 57 & 58 & 59 \\
\hline $\begin{array}{l}\text { Average value } \\
\text { of density of } \\
\text { steam, } \mathrm{kg} / \mathrm{m}^{3}\end{array}$ & $16 \cdot 10^{-2}$ & $19 \cdot 10^{-2}$ & $26 \cdot 10^{-2}$ & $36 \cdot 10^{-2}$ \\
\hline $\begin{array}{l}\text { Average speed } \\
\text { of the thermal } \\
\text { movement } \\
\text { molecules, } \mathrm{m} / \mathrm{s}\end{array}$ & $6,23 \cdot 10^{2}$ & $6,24 \cdot 10^{2}$ & $6,24 \cdot 10^{2}$ & $6,26 \cdot 10^{2}$ \\
\hline $\begin{array}{l}\text { Average length } \\
\text { of a free run } \\
\text { molecules, } \mathrm{m}\end{array}$ & $0,4 \cdot 10^{-6}$ & $0,37 \cdot 10^{-6}$ & $0,28 \cdot 10^{-6}$ & $0,22 \cdot 10^{-6}$ \\
\hline $\begin{array}{c}\text { Coefficient of } \\
\text { diffusion, } . \mathrm{m}^{2} / \mathrm{s}\end{array}$ & $0,83 \cdot 10^{-4}$ & $0,76 \cdot 10^{-4}$ & $0,58 \cdot 10^{-4}$ & $0,45 \cdot 10^{-4}$ \\
\hline $\begin{array}{c}\text { Volume of } \\
\text { moisture, } \mathrm{m}^{3}\end{array}$ & $3,51 \cdot 10^{-14}$ & $5,25 \cdot 10^{-14}$ & $5,84 \cdot 10^{-14}$ & $6,09 \cdot 10^{-14}$ \\
\hline $\begin{array}{l}\text { The calculated } \\
\text { mass of } \\
\text { moisture of } \\
\text { microcapillaries } \\
\text { as a result of the } \\
\text { sorption } \\
\text { phenomena (9), } \\
\%\end{array}$ & 9,5 & 13,5 & 15,3 & 16,0 \\
\hline $\begin{array}{c}\text { The mass of } \\
\text { moisture } \\
\text { calculated by a } \\
\text { formula as a } \\
\text { result of heat } \\
\text { exchange (10), } \\
\% \\
\end{array}$ & 2,5 & 2,6 & 2,7 & 2,8 \\
\hline The total & 12,0 & 16,1 & 18,0 & 18.8 \\
\hline
\end{tabular}
moistening

\begin{tabular}{|c|c|c|c|c|}
\hline $\begin{array}{l}\text { calculated mass } \\
\text { of moisture, } \%\end{array}$ & & & & \\
\hline $\begin{array}{c}\text { The calculated } \\
\text { relative } \\
\text { humidity of } \\
\text { samples of skin, } \\
\%\end{array}$ & $\begin{array}{c}18,0+12,0= \\
=30\end{array}$ & $\begin{array}{c}18,0+16,1= \\
=34.1\end{array}$ & $\begin{array}{c}18,0+18,0= \\
\quad=36,0\end{array}$ & $\begin{array}{c}18,0+18,8= \\
=36,8\end{array}$ \\
\hline
\end{tabular}

The time of maximum filling of the microcapillary with moisture calculated according to the formula $(9,10)$ will be 480s [10] (the relative humidity of the leather samples is $36,8 \%$ and this value can be recommended with intensified hygrothermal treatment of natural skins in the corresponding equipment [17-20].

\section{References}

1. L.V. Larina, N.Yu. Leshina Technical and technological problems of service 3, 42-44 (2014)

2. L.V. Larina, Proceedings of IGTA conference, (Progress-2012), Ivanovo, 163-164 (2012)

3. L.V. Larina, Research of the process and development of the installation for vacuum-sorption humidification of the upper parts of the shoe: dis.... cand. tech. Sciences, Moscow, (1991)

4. M.U. Kuramysov, Yu.V. Bondareva, E.I. Bitus Izv. universities. Technology of the textile industry, No. 3m, 110-112. (2015)

5. V.M. Janpayzova, Izv. universities. Technology of the textile industry, No. 6. 124-126 (2013)

6. L.V. Larina V.A. Pershin, Engineering bulletin of Don, No. 3. (2012) Access mode: http://www.ivdon.ru/ru/magazine/archive/n3y2012/9 02 . - The mass media registration certificate Al No. FS77-27308 from 2/22/2007

7. L.V. Larina, V.V. Smirnov, Design of mechanisms of cars of systems of service and light industry: a laboratory practical work for bachelors (ISOiP (branch) of DSTU in Shakhty, Shakhty, 2014), ISBN 978-5-93834-911-7, Access mode: http://www.libdb.sssu.ru

8. R.V. Lutsyk, Development of methods of study, analysis of interrelation and forecasting of heat and mass exchange and physico-mechanical properties of textile and leather-shoe materials: dis.... Doct. tech. Sciences, Kiev (1987).

9. L.V. Larina Vacuum and capillary gigrotermichesky processing of skin of L.V. Larin (ИСОиП (branch) of DGTU, Shakhty, 2014)

10. L.V. Larina, N. Yu. Leshina, V.V. Smirnov, Current problems of the equipment and technology: proceedings, Shakhty, 158-162 (2014)

11. L. In Larina, V. A., Pershin Smirnov V. In, Dzheliyev Yu.O Patent No. 2447822 Russian Federation, MPK A43D 11/10

12. G. Korn Handbook on Mathematics for Scientists and Engineers (Nauka, Moscow, 1970) 
13. Larina L.V. Izvestiya Vuzov. North-Caucasus. region. Technical science,Novocherkassk: YURSTU, 140-145 (2011)

14. L.V. Larina, Izvestiya Vuzov. North-Caucasus. region, technical sciences, Novocherkassk: YURSTU, No. 1, 129-132 (2012)

15. G. Kramer, Mathematical methods of statistics, (Mir, Moscow, 1975).

16. L.V. Larina, V.V. Karaschenko, World Applied Sciences Journal, 29, N 12, (2014) Access mode: http:www.idosi.org/wasj/wasj/29\%2812\%292014.ht $\mathrm{m}$

17. LV. Larina, A.A. Zagoskin, A.A. Small, etc. Pat. 2312574 Russian Federation IPC6, A 43 D 95/10.

18. LV. Larina, V.V. Smirnov, B.I. Surmilov et al. Pat. 2414832 Russian Federation IPC6, A 43 D 11/10.

19. Larin L.V., Smirnov V. V., Tikhonov O. B., Smirnov E. I. Pat. No. 2537160 the Russian Federation, MPK A43D 11/00

20. Larina L.V. ITNO-2017: Proc. V International scientific and practical conference DSTU, 410-415 (2017) 